\title{
Classifying Personal Colors Using Lipstick Colors
}

Do-Eun $\mathrm{Kim}^{1}$, Young-Sam Kim²*

${ }^{1}$ Department of Cosmetics Engineering, Konkuk University, Seoul, Korea

${ }^{2}$ Department of Image Industry, Graduate School of Engineering, Konkuk University, Seoul, Korea

*Corresponding author: Young-Sam Kim, Department of Image Industry, Graduate School of Engineering, Konkuk University, 120 Neungdong-ro, Gwangjin-gu, Seoul 05029, Korea

Tel.: +82 24500463

Email: gracehelen@konkuk.ac.kr

Received July 23, 2020

Revised September 08, 2020

Accepted September 10, 2020

Published September 30, 2020

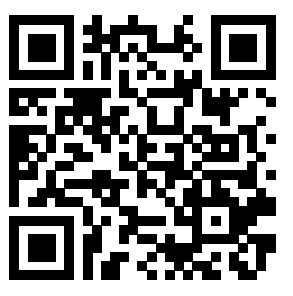

\begin{abstract}
Purpose: The study argues for the use of lipstick colors in the classification of personal color types. Methods: Data were collected from 60 women aged 20-39 years, living in the Seoul metropolitan area. The study conducted $x^{2}$-test and frequency analysis, one-way ANOVA, cluster analysis, and discriminant analysis. Results: A significant difference was not observed between the best color drape and color change of the skin after lipstick application. Therefore, lipstick color alone classifies the type without drape. Conclusion: The study demonstrated the correlation between diagnostic cloth and lipstick color according to personal color type and confirmed that a system can be used to classify the type by lipstick color alone without a personal color diagnostic cloth. Based on this theory, it can be used as a basic material in the field of cosmetology.
\end{abstract}

Keywords: Personal color, Make-up, Lipstick, Image, Cosmetic color

\section{Introduction}

현대사회에서 이미지의 생산 및 전달은 중요한 커뮤니케이션 활 동으로 인식된다. 주변의 모든 사물에서 사람까지 이미지에 의해 많 은 영향을 받고 있으며, 개인의 이미지는 첫 만남의 짧은 순간 타인 에게 보이는 바에 의해 평가되며 결정된다(Lee \& Park, 2012). 특 히 여성의 경우 사회 참여와 전문화가 가속됨에 따라 자신의 이미지 를 표현할 기회가 많아지고 외모에 대한 관심도 더욱 높아지게 되 는 경향이 있다(Cho \& Yang, 2017). 외모가 경쟁력이 되는 현시대 에(Sim \& Choi, 2017) 외모도 능력의 일부라는 사회적 인식이 지배 적이다(Jin \& Cho, 2009). 자신의 이미지가 타인이 보는 관점에 의 해 중요하게 판단됨에 따라(Kim, 2016) 개성을 표출하기 위하여 여 성들은 의복, 액세서리, 화장을 도구로 활용하고 있다(Woo \& Kim, 2011). 매력을 결정하는데 핵심적인 부분인 얼굴을 미적인 측면에 서 향상시키는 것은 메이크업으로(Park, 2003). 얼굴의 불만족스러 운 부분을 감추면(Baek \& Kim 2004). 자신감이 생겨 적극적으로 자기를 표현하게 된다(Hwang et al., 2003; Kwon et al., 2019).
또한 메이크업은 대인지각 시 후광효과로 작용하여 커뮤니케이션 수단으로써(Kim \& Kang, 2003). 긍정적 이미지 연출 및 아름다움 에 대한 욕구를 충족시켜줄 수 있는 중요한 도구가 되고 있다(Kim, 2011).

이미지는 주관적 판단으로 이루어지나 그것을 형성하고 좌우하는 역할 중의 하나가 컬러이다(Kim, 2016). 특히 컬러는 자아를 표현 하는데 있어 가장 확실한 수단으로서(Oh \& Cho, 2018), 사람의 감 정을 자극하는 컬러 고유의 언어적-시각적 이미지로 그중 메이크업 이미지를 설정하는데 매우 중요한 요소가 되기도 한다(Cho, 2018). 메이크업은 시각적으로 나타나는 컬러(color)를 사용하여 얼굴에 결 점을 보완하고 아름다움을 표현하는 방법으로서, 개인이 타고난 외 모에 조화로운 색채를 배색하는 행위이다(Song et al., 2014). 요 즘 메이크업 및 패션의 경향은 보편적인 미의 기준을 모사하기보다 는, 자신이 가진 장점을 살리고, 약점을 보완하여 자기 자신에게 가 장 잘 맞는 미를 찾아내고자 하는 쪽으로 흘러가고 있다(Kim et al, 2018). 색은 그 사람에게 잘 어울려서 좋은 인상을 형성해 줄 수도 있으며, 반대로 어울리지 않는 색으로 인해 부정적인 인상을 줄 수 
도 있다. 현대 사회에서 개인이 만드는 자신의 이미지는 실제 자아 의 모습이라기 보다는 스스로가 이상적으로 다른 사람에게 좋게 보 이기를 바라는 모습이다(Whang et al., 1999). 자신의 이미지 개선 을 위한 화장색, 의상색을 선택할 때 얼굴을 중심으로 신체의 색과 조화를 이뤄 피부색이 아름답고 건강하게 보이는 색채를 퍼스널 컬 러라고 한다(Im et al., 2017).

이러한 경향에 맞춰 퍼스널 컬러(personal color)에 대한 연구가 고도화되고 대중의 관심이 급격히 성장하고 있다(Lee et al., 2018). 개인색채와 의복색에 대해 관심을 가지기 시작한 것은 1960 년대부 터이며, 1980년에 이르러 캐롤잭슨이 개인색채를 4 계절로 분류하였 다(Park, 2001). 캐롤잭슨은 신체의 3색소인 헤모글로빈, 카로틴, 멜라닌의 분포에 의해 따뜻한 톤과 차가운 톤의 피부로 구분하였고, 따뜻한 톤의 피부는 노르스름한 톤(golden undertone)으로 봄과 가 을로, 차가운 톤의 피부는 푸르스름한 톤(blue undertone)으로 여름 과 겨울로 분류하였다(Jackson, 1980). 웜 톤과 쿨 톤을 분류한 후 에 다시 4 계절 시스템으로 분석하는 것은 일반적으로 알려진 사실이 다. 단일 민족인 한국인의 경우 서양인과 달라서 신체 색의 차이가 크지는 않지만, 같은 타입 안에서도 개인별 특징이 존재한다(Moon \& Park, 2014). 한국인의 퍼스널 컬러 표준이 될 수 있는 피부 유형 에 대한 기초 연구가 계속되고 있고 뷰티-패션 업계에서는 퍼스널 컬러를 이용한 마케팅의 사례가 늘고 있다(Park et al.,2019). 이러 한 시장 변화에 미용서비스업의 종사자는 전문적인 분야로 지식과 기술, 정보의 증가에 맞춰 고객에게 미적 만족을 주는 업무를 수행 (Min et al., 2013; Park et al., 2020).하기 위해 고객들의 색상 선 택에 도움을 주고자 퍼스널 컬러 전문가에게 재교육을 받고 있는 실 정이다. 하지만 현실적으로 현장에서 퍼스널 컬러를 구분하기란 쉽 지 않다. 일단 색은 빛에 반사되어 보이는 것으로 광원의 영향을 받 는데 현장에는 어둡고 노란 빛이 도는 조명이 많다. 또한 진단자의 주관이 개입되므로 숙련된 진단자가 공통적으로 조화되는 요소를 고려하여 퍼스널 컬러 유형을 찾아야 한다. 숙련된 진단자와 환경이 갖춰져도 영업 현장에서는 퍼스널 컬러 진단을 할 수 있는 여건이 여의치 않은 것이 사실이다. 기존 퍼스널 컬러 진단에 대한 선행 연 구는 분광측색계로 피부색을 측색한 연구와, 웜톤, 쿨톤으로 진단된 2 명의 모델 혹은 4 계절 유형으로 진단된 4 명의 모델에게 베스트 컬 러, 워스트 컬러의 진단천이나 메이크업을 적용한 자극물을 제작한 후 일반인 혹은 전문가를 대상으로 조화, 부조화를 알아본 설문조사 연구가 많았다. 그러나 자극물을 제작하는 과정에서 카메라가 자체 보정이 되거나 조명으로 인한 빛의 간섭으로 사람의 눈으로 보는 것 만큼 색을 담아내는 데는 한계가 있었다.

따라서 본 연구는 연구자가 분광측색계로 피부색 측색을 한 후 진 단 천으로 유형을 파악하고 분석한다. 연구대상자에게는 유형을 공 개하지 않고 베스트 컬러와 워스트 컬러를 댄 진단 천과 립스틱 컬 러를 적용해 본 후 직접 본인이 느끼는 조화, 부조화에 대한 설문조 사를 하여 진단 천과 립스틱과의 상관관계를 증명하고 립스틱만으
로도 자기 유형을 파악할 수 있는지 알아보고자 한다.

\section{Methods}

\section{1.연구참여자 및 기간}

본 연구는 수도권에 거주하는 20-39세의 여성들 중 인공태닝 및 피부과 시술한 자, 질병에 의해 피부에 영향을 미치는 자, 외국거주 자, 기관생명윤리위원회 심의에 의거 객관성을 담보하기 어려운 학 생 신분을 제외한 60 명을 대상으로 건국대학교 기관생명윤리위원회 (IRB)의 연구승인(7001355-201910-HR-339)을 받고 진행하였으 며 연구대상자에게 시험을 통해 연구하려는 목적과 절차 등의 내용 을 상세히 설명한 후 동의를 구하였다. 시험기간은 2019년 11월 8 일부터 11월 18 일까지 총 11일간에 1차와 2차로 나누어 진행하였 다.

\section{2. 측정 도구 및 방법}

\section{1) 측정도구}

본 연구에서는 연구대상자의 정량적인 피부색과 입술색, 신체 색을 측정하기 위하여 분광측색계(Minolta-CM-2500d; Kenis, Japan)를 이용한 측색평가와 진단천(Drape; K.F.P Institute, Korea), (drape; VST Lap, Korea)]을 이용한 관능평가로 시험을 진 행하였다. 진단천마다 유형의 상이한 부분은 배제하여 객관성을 높 였고 퍼스널 컬러 유형 진단을 위한 색상의 기준은 4계절 유형 색 상을 토대로 명도를 나타내는 light, medium, dark 3 가지를 적용 한 분류 방법을 채택하였다. 또한 립스틱은 기존 선행연구에서 진행 한 립스틱이 단종되거나 구입하기에 접근성이 떨어진 경우가 있어 일반인 및 연구자의 접근성이 좋고 다양한 컬러를 가지고 있는 브 랜드 중 리뉴얼 되면서 단종되기 쉬운 국내브랜드를 제외한 립스틱 (Lipstick; Mac, Canada)을 선택하였다.

\section{2) 측정방법}

측정 전 분광측색계의 측색 면을 알코올 솜으로 깨끗이 닦은 뒤, 세안 후 안정을 취한 연구대상자의 이마, 볼, 턱, 턱밑, 입술, 손바닥 총 6 곳의 부위를 3 회 반복 측정하여 $\mathrm{CIE}$ 의 $\mathrm{L}^{*} \mathrm{a}^{*} \mathrm{~b}^{*}$ 값으로 표기하였 다. 진단천으로 진단 시 정확한 유형 분석을 위해 안경, 컬러렌즈는 제거하도록 하고 연구대상자의 헤어와 의상색상에 영향을 받지 않 도록 흰색 터번과 흰색 케이프를 어깨에 둘러 진단에 영향을 줄 수 있는 외부 환경을 표준화하였다. 계절과 날씨에 따른 영향을 받지 않는 동일한 환경을 조성하기 위해 자연광과 흡사한 $5000 \mathrm{k}$ 의 색온 도를 내는 조명 램프를 사용하였다.

\section{3) 립스틱 색상선정}

입술색에 따른 립스틱 발색에 관한 연구에서 사용된 립스틱 색상 
을 바탕으로, Ko \& Ryu (2009)의 연구에서 공통적으로 사용된 레 드 브라운, 핑크, 오렌지, 베이지, 와인 색상을 참고하였다. 다만 본 연구가 립스틱 색상으로 퍼스널 컬러를 알아보고자 하였고, 현재까 지는 명도별 립스틱에 관한 연구가 없는 실정이므로 명도별 대표 립 스틱을 본 연구자가 직접 선정하여 본 시험에 사용하였다. 립스틱 은 혈색을 부여해주기 위한 도구로 붉은 계열의 색상이 주를 이루 며, 피부색의 변화도는 붉은 색상 적용 시 관찰하기가 쉽다. 본 연구 에서는 각 계절의 대표적인 특징을 가지고 있는 베스트 컬러의 붉은 색 계열 립스틱을 선정하였다. 유형별 베스트 컬러 진단 천의 색상 을 먼셀 기호로 제시한 Hong (2005)의 연구를 참고하여 유형별 진 단 천의 베스트 컬러를 유형과 명도에 따라 립스틱 컬러로 변환하여 제시하였다. 본 연구의 명도별 드레이프 먼셀 값에 따른 립스틱 색 상의 결과는 Table1과 같다.

\section{4) 립스틱 적용 방법}

립스틱 적용 방법은 연구대상자의 왼쪽 위·아랫입술과 오른쪽 위·아랫입술 각각 반쪽씩 립스틱 색상을 적용한다. 이는 입술의 형 태적인 면을 완전히 배제할 수 없지만 색이 시 감각에 먼저 들어와
형태적인 면의 영향이 적어지도록 하고, 반쪽씩 입술을 가려서 비 교 분석할 수 있도록 하기 위해서이다. 먼저 스틸 파레트에 립스틱 내용물을 $0.3 \mathrm{~g}$ 씩 나이프로 덜어 동일한 양을 조절하였고, 일회용 립 브러쉬를 사용하여 기존의 사용했던 색과 섞이지 않게 시험하였 다. 또한 립스틱을 적용할 때 연구대상자의 입술색의 영향이 드러 나지 않게 3-4회 발색을 하여 립스틱 본연의 발색이 나타나게 하였 고 립스틱을 지우고 다른 립스틱을 도포할 때, 입술 전용 리무버를 사용하여 화장 솜으로 도포된 립스틱의 잔여물을 깨끗하게 세정한 후 진행하였다. 이 때, 지우는 과정에서 마찰로 인한 입술색의 적색 도가 일시적으로 상승할 수 있으므로 5 분간의 휴식을 취한 후, 입술 색이 안정화되었을 때 다른 색채의 립스틱을 도포하여 실험을 진행 하였다. 립스틱과 일회용 립 브러쉬를 적용한 연구대상자의 모습은 Figure 1, Figure 2와 같다.

\section{5) 설문지}

본 연구에서 립스틱 색채를 이용한 퍼스널 컬러 분류 연구를 위해 사용된 육안 측색지와 시험 전후 설문지는 Kim \& Youn (2018)의 선행연구에서 실시된 측정항목을 토대로 본 연구의 목적에 맞게 문

\section{Table 1. Munsell of drape and lipstick by lightness}

\begin{tabular}{|c|c|c|c|c|}
\hline Type & & Lightness & Color analysis drapes & Lipstick colors \\
\hline \multirow{6}{*}{ Warm tone } & & Light & & \\
\hline & Spring & Medium & & \\
\hline & & Dark & & \\
\hline & & Light & & \\
\hline & Autumn & Medium & & \\
\hline & & Dark & & \\
\hline \multirow{6}{*}{ Cool tone } & & Light & & \\
\hline & Summer & Medium & & \\
\hline & & Dark & & \\
\hline & \multirow{3}{*}{ Winter } & Light & & \\
\hline & & Medium & & \\
\hline & & Dark & & \\
\hline
\end{tabular}




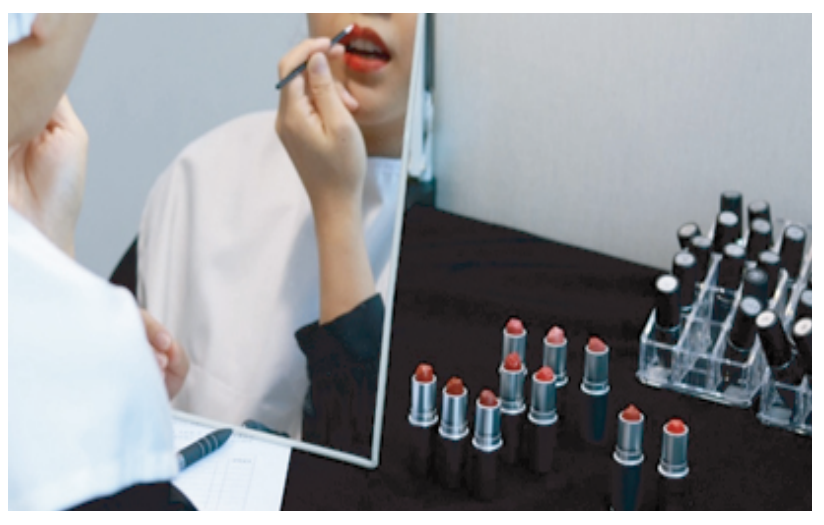

Figure 1. Subject's lipstick application.

항을 수정, 보완하여 재구성하여 제작한 설문지를 사용하였다. 또한 시험 전 설문지는 크게 3 가지 요인으로, 인구통계학적 특성 6 문항, 베스트 컬러 드레이프 적용 후 얼굴의 피부색 변화도 11 문항, 베스 트 립스틱 컬러 적용 후 얼굴의 피부색 변화도 12 문항으로 각각 구 성하였다.

\section{6) 자료분석}

본 연구의 수집된 자료는 SPSS WIN 25.0 프로그램을 이용하여 분석하였다. 분석기법으로는 연구대상자의 일반적 특성을 살펴보 기 위해 빈도와 백분율을 구하였다. 또한 여성들의 퍼스널 컬러 유 형에 따른 신체 색상 분포와 피부색의 $\mathrm{L}^{*} \mathrm{a}^{*} \mathrm{~b}^{*}$ 값을 알아보기 위해 $\chi$ ${ }^{2}$ (Chi-square) test와 빈도분석, One-way ANOVA (일원변량분석) 을 실시하였고 신뢰수준 $95 \%(\alpha=0.05)$ 에서 각 항목 값을 분석한 후 산출된 $p$-value를 통해 통계적 유의성 여부를 검증하였다.

\section{Results and Discussion}

\section{1. 연구참여자의 일반적 특성}

본 연구의 연구 참여자의 일반적 특성은 Table 2 와 같으며, 총 60 명 중 성별은 여자 $100 \%$, 연령별로는 28-31세가 $31.7 \%$ 로 가 장 많았으며, 다음으로 32-35세 25.0\%, 20-23세 21.7\%, 24-27 세 $16.7 \%, 36-39$ 세 $5.0 \%$ 순으로 나타났다. 거주지별로는 서울시 가 $70.0 \%$ 로 대부분을 차지하였으며, 다음으로 경기도 $26.7 \%$, 인천 시 $3.3 \%$ 순이었다. 결혼여부별로는 미혼이 $86.7 \%$ 로 대부분을 차지 하였으며, 기혼은 $13.3 \%$ 이었다. 최종학력으로는 대졸 $75.0 \%$ 로 가 장 높은 분포를 보였으며, 다음으로 대학원졸(재) $15.0 \%$, 전문대졸 $8.3 \%$, 고졸 1 명으로 $1.7 \%$ 순으로 차지하였다. 직업별로는 회사원이 $53.3 \%$ 로 가장 높은 분포를 보였으며, 다음으로 기타 $13.4 \%$, 주부/ 무직과 자영업/서비스업 $11.7 \%$, 공무원 $6.7 \%$, 전문직 $3.3 \%$ 순으

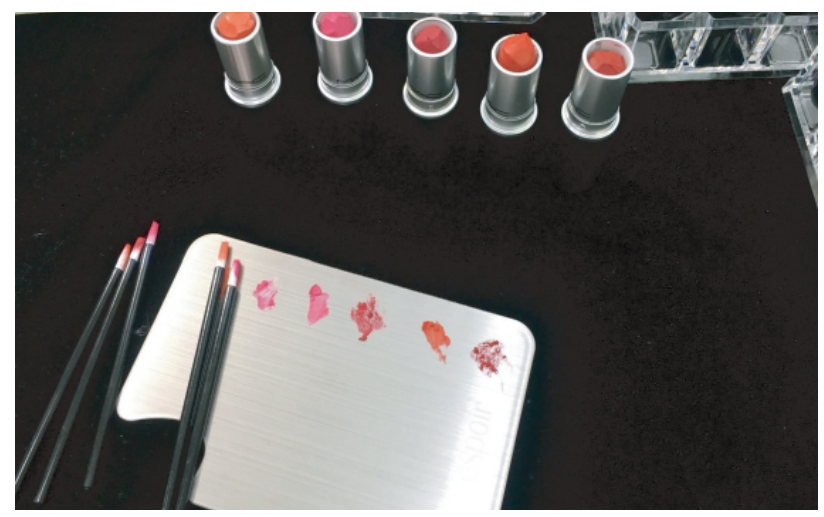

Figure 2. Lipstick and lip brush.

로 차지하였다. 월평균 소득별로는 200-300만원 미만이 36.7\%로 가장 많았으며, 다음으로 100 만원 미만 $26.7 \%, 300-400$ 만원 미만 $18.3 \%, 100-200$ 만원 미만 $13.3 \%, 500$ 만원 이상 3.3\%, 400-500 만원 미만 $1.7 \%$ 순으로 나타났다.

\section{2. 퍼스널 컬러 유형에 따른 피부색 $L^{*} a^{*} b^{*}$ 값}

전체적으로 피부색의 $\mathrm{L}^{*}$ 값은 봄 유형이 가장 높았고, 겨울 유형 은 다른 유형보다 낮았으며, 퍼스널 컬러 유형에 따라 유의미한 차 이를 보였다( $F=23.38, p<0.001) . \mathrm{a}^{*}$ 값 $(F=13.97, p<0.001)$ 과 $\mathrm{b}^{*}$ 값 ( $F=28.89, p<0.001)$ 은 겨울 유형이 가장 높았고, 봄 유형은 다른 유 형보다 낮았으며, 퍼스널 컬러 유형에 따라 유의미한 차이를 보였 다. 이상에서 여성들의 퍼스널 컬러 유형에 따라 피부색의 $\mathrm{L}^{*} \mathrm{a}^{*} \mathrm{~b}^{*}$ 값 에 대해 살펴본 결과, 피부의 명도 $\left(\mathrm{L}^{*}\right)$ 는 봄 유형이 다른 유형보다 높고, 적색도 $\left(\mathrm{a}^{*}\right)$ 와 황색도 $\left(\mathrm{b}^{*}\right)$ 는 겨울 유형이 다른 유형보다 높음을 알 수 있다. 여성들의 퍼스널 컬러 유형에 따라 피부색의 $\mathrm{L}^{*} \mathrm{a}^{*} \mathrm{~b}^{*}$ 값에 대해 살펴본 결과는 Table 3 과 같다.

\section{3. 퍼스널 컬러 유형에 따른 베스트 컬러 드레이프와 립스틱 적용 후 얼굴 피부색의 조화요인과 부조화요인}

베스트 컬러를 적용한 붉은색 및 노란색 빛의 감소는 드레이 프는 겨울이 $100 \%$, 여름이 $94.4 \%$, 봄 $80.0 \%$, 가을 $76.2 \%$ 순으 로 나타났다. 립스틱은 여름 $94.4 \%$, 가을 $90.5 \%$, 봄 $86.7 \%$, 겨울 $83.3 \%$ 순으로 나타났다. 드레이프와 립스틱 적용한 후 붉은기와 노 란기가 전체적으로 감소하는 것을 알 수 있었다. 베스트 컬러를 적 용 후 명도가 밝아진다라고 느낀 비율은 드레이프는 봄과 여름이 $100 \%$, 가을 $90.5 \%$, 겨울 $66.7 \%$ 순으로 나타났다. 립스틱은 봄, 겨 울이 $100 \%$, 여름 $94.4 \%$, 가을이 $85.7 \%$ 순으로 나타났다. 베스트 컬러를 적용 후 채도가 투명해진다라고 느낀 비율은 드레이프 여 름 $94.4 \%$, 봄과 겨울이 $66.7 \%$, 가을 $52.4 \%$ 순으로 나타났다. 립스 틱은 여름 $88.9 \%$, 봄 $80 \%$, 겨울 $66.7 \%$, 가을 $52.4 \%$ 순으로 나타 
났다. 피부가 투명해진다 라고 느낀 비율이 여름이 많은 이유는 붉 은기가 감소하면서 자신이 가지고 있던 연하고 투명한 피부가 색에 반사되어 더 투명해진다 라고 느끼는 것 같았다. 베스트 컬러를 적 용 후 균일하다고 느낀 비율은 드레이프는 봄, 여름, 가을이 $100 \%$, 겨울이 $66.7 \%$ 순으로 나타났다. 립스틱 가을 $100 \%$, 봄 $93.3 \%$, 여 름 $88.9 \%$, 겨울 $50 \%$ 순으로 나타났다. 자신의 피부톤과 베스트 컬 러가 잘 매치 됐을 때 피부의 잡티와 기미, 붉은기와 노란기 감소 로 전체적으로 피부가 균일해지는 것을 느낄 수 있었다. 베스트 컬 러를 적용 후 혈색이 좋아보인다 라고 느낀 비율은 드레이프는 겨 울 $100 \%$, 봄 $93.3 \%$, 가을 $90.5 \%$, 여름 $88.9 \%$ 순으로 나타났다. 립 스틱은 봄, 가을, 겨울 $100 \%$, 여름 $83.3 \%$ 순으로 나타났다. 전체적 으로 혈색이 좋아보인다고 느꼈고 4계절 중 겨울 유형이 베스트 컬 러를 적용했을 때 혈색이 더 살아나는 것을 알 수 있었다. 베스트 컬 러를 적용 후 피부가 좋아보인다 라고 느낀 비율은 드레이프는 여 름 $83.3 \%$, 가을 $81.0 \%$, 봄 $73.3 \%$, 겨울 $50 \%$ 순으로 나타났다. 립
스틱은 여름 $83.3 \%$, 가을 $76.2 \%$, 봄 $60 \%$, 겨울 $50 \%$ 순으로 나타 났다. 베스트 컬러를 적용 후 입체적이다 라고 느낀 비율은 드레이 프는 겨울 $83.3 \%$ 봄 $53.3 \%$ 여름 $50.5 \%$ 가을 $38.1 \%$ 순으로 나타났 다. 립스틱은 봄, 가을, 겨울 $66.7 \%$, 여름 $55.6 \%$ 순으로 나타났다. 고채도가 잘 어울리는 유형일수록 자신과 맞는 베스트 컬러를 적용 했을 때 이목구비가 뚜렷하게 입체적으로 보였다. 베스트 컬러를 적 용 후 얼굴의 각은 드레이프는 가을 $90.5 \%$,여름 $83.3 \%$, 봄 $66.7 \%$, 겨울 $16.7 \%$ 순으로 나타났다. 립스틱은 가을 $76.2 \%$, 여름 $72.2 \%$, 봄 $33.3 \%$, 겨울 $16.7 \%$. 순으로 나타났다. 베스트 컬러를 적용 후 광 대에서 턱 라인 부분 얼굴의 형태가 부드럽게 완화되어 보인다고 느 꼈다. 베스트 컬러를 적용 후 잡티, 기미, 여드름이 희미해진다 라 고 느낀 비율은 드레이프는 여름 $94.4 \%$, 봄 $80.0 \%$, 가을 겨울이 $66.7 \%$ 순으로 나타났다. 립스틱 여름 $100 \%$, 봄, 겨울 $66.7 \%$, 가 을 $52.4 \%$ 순으로 나타났다. 워스트 컬러를 적용한 경우 얼굴의 요 철이 도드라지지만 베스트 컬러에서 희미해지는 것을 여름과 봄 유

Table 2. General characteristics of study subjects

\begin{tabular}{|c|c|c|c|}
\hline Classification & & Frequency & Percent (\%) \\
\hline \multirow{5}{*}{ Age group } & $20-23$ & 13 & 21.7 \\
\hline & $24-27$ & 10 & 16.7 \\
\hline & $28-31$ & 19 & 31.7 \\
\hline & $32-35$ & 15 & 25.0 \\
\hline & $36-39$ & 3 & 5.0 \\
\hline \multirow{3}{*}{ Area } & Seoul & 42 & 70.0 \\
\hline & Incheon & 2 & 3.3 \\
\hline & Gyeonggi-do & 16 & 26.7 \\
\hline \multirow{2}{*}{ Marital status } & Single & 52 & 86.7 \\
\hline & Married & 8 & 13.3 \\
\hline \multirow{4}{*}{ Education } & High school graduate & 1 & 1.7 \\
\hline & College graduate & 5 & 8.3 \\
\hline & University graduate & 45 & 75.0 \\
\hline & Graduate degree or higher & 9 & 15.0 \\
\hline \multirow{6}{*}{ Career } & Housewife/Inoccupation & 7 & 11.7 \\
\hline & Office worker & 32 & 53.3 \\
\hline & Profession & 2 & 3.3 \\
\hline & Self-employment/Service job & 7 & 11.7 \\
\hline & Civil servant & 4 & 6.7 \\
\hline & Etc. & 8 & 13.4 \\
\hline \multirow{6}{*}{ Average monthly income } & Less than 1 million won & 16 & 26.7 \\
\hline & 1-less than 2 million won & 8 & 13.3 \\
\hline & 2-less than 3 million won & 22 & 36.7 \\
\hline & 3-less than 4 million won & 11 & 18.3 \\
\hline & 4-less than 5 million won & 1 & 1.7 \\
\hline & Over 1 million won & 2 & 3.3 \\
\hline Total & & 60 & 100.0 \\
\hline
\end{tabular}


형에서 가장 많이 느꼈다. 얼굴의 명도가 밝을수록 얼굴의 잡티가 더 희미하거나 완화되는 것을 잘 느꼈다. 베스트 컬러를 적용 후 주 름, 그늘이 옅어진다 라고 느낀 비율은 드레이프 가을 $95.2 \%$, 봄 $93.3 \%$, 여름 $88.9 \%$, 겨울 $83.3 \%$ 순으로 나타났다. 립스틱 여름, 겨 울 $83.3 \%$, 봄 $73.3 \%$, 가을 $71.4 \%$ 순으로 나타났다. 전체 유형에서 주름과 그늘이 옅어진다고 느낀 비율이 높았다. 베스트 컬러를 적용 후 전체적인 분위기가 조화롭다고 느낀 비율은 드레이프는 봄, 가을 이 $100 \%$, 여름 $94.4 \%$, 겨울 $83.3 \%$ 순으로 나타났다. 립스틱은 4 계 절 모두 $100 \%$ 조화롭다고 느꼈다. 전체 유형에서 분위기가 조화롭 다고 느꼈다. 베스트 컬러를 적용 후 립스틱과 입술이 떠 보이지 않 고 밀착되었다고 느낀 비율은 4계절 모두 $100 \%$ 였다. 균일성, 얼굴 의 각, 주름\&그늘 항목에서는 드레이프가 높았고 입체성, 전체적인 분위기는 립스틱 컬러를 적용했을 때 높게 나타났다. 피부색에서 붉 은색 및 노란색은 드레이프 보다 립스틱 컬러를 적용한 후에 감소하 였으나 유의미한 차이는 아니었다. 피부의 명도와 채도는 드레이프 적용과 립스틱 컬러 적용 모두 큰 변화 없이 밝아졌고, 투명 해졌다. 피부의 균일성은 립스틱 컬러 적용보다 드레이프 적용 후 균일해 보 였으나 통계적으로는 유의미한 차이를 보이지 않았다. 혈색은 드레 이프 보다 립스틱 컬러를 적용한 후에 좋아 보였고, 피부는 립스틱
컬러 적용보다 드레이프 적용 후 좋아 보였으나 유의미한 차이는 아 니었다. 얼굴형태의 입체성은 드레이프 보다 립스틱 컬러를 적용한 후에 입체적이었고, 얼굴의 각은 립스틱 컬러 적용보다 드레이프 적 용 후 부드러워졌으며, 잡티, 기미, 여드름도 립스틱 컬러 적용보다 드레이프를 적용 후 희미 해졌으나 통계적으로는 유의미한 차이를 보이지 않았다. 주름, 그늘은 립스틱 컬러 적용보다 드레이프 적용 후 옅어졌고, 드레이프 보다 립스틱 컬러를 적용한 후에 변화가 없 었으며, 통계적으로도 유의미한 차이를 보였다 $\left(\chi^{2}=5.07, p<0.05\right)$. 인상의 전체적인 분위기는 드레이프 보다 립스틱 컬러를 적용한 후 에 조화로웠으나 유의미한 차이는 아니었다.

이상에서 여성들의 퍼스널 컬러 유형에 따라 드레이프 적용 후와 립스틱 컬러를 적용한 후에 얼굴 피부색의 조화요인과 부조화요인 에 대해 살펴본 결과, 주름, 그늘 항목 외에는 유의미한 차이가 없음 을 알 수 있었다. 여성들의 퍼스널 컬러 유형에 따라 드레이프 적용 후와 립스틱 컬러를 적용한 후에 얼굴 피부색의 조화요인과 부조화 요인에 대해 살펴본 결과는 Table 4 와 같다.

\section{4. 퍼스널 컬러 유형에 따른 립스틱 적용 결과}

먼저 Table 5-1의 연구대상자는 웜톤 봄 미디엄 유형으로 베스트

Table 3. Average values of skin color types by four seasons

\begin{tabular}{|c|c|c|c|c|c|c|c|c|c|c|c|}
\hline \multirow{2}{*}{\multicolumn{2}{|c|}{ Classification }} & \multicolumn{2}{|c|}{ Spring } & \multicolumn{2}{|c|}{ Summer } & \multicolumn{2}{|c|}{ Autumn } & \multicolumn{2}{|c|}{ Winter } & \multirow{2}{*}{$F$} & \multirow{2}{*}{$p$} \\
\hline & & $M$ & SD & $M$ & SD & $M$ & SD & $M$ & SD & & \\
\hline \multirow{3}{*}{ Forehead } & $L^{*}$ & 63.39 & 2.61 & 62.04 & 2.46 & 58.46 & 1.52 & 55.67 & 2.26 & $27.30^{* * *}$ & 0.000 \\
\hline & $a^{*}$ & 11.23 & 1.32 & 11.46 & 1.62 & 13.52 & 1.41 & 14.43 & 1.57 & $13.56^{* * *}$ & 0.000 \\
\hline & $b^{*}$ & 15.19 & 1.43 & 17.15 & 2.00 & 19.16 & 2.01 & 20.79 & 1.22 & $20.34^{* * *}$ & 0.000 \\
\hline \multirow{3}{*}{ Cheek } & $L^{*}$ & 65.55 & 2.42 & 64.64 & 2.41 & 62.15 & 1.91 & 60.49 & 2.68 & $11.57^{* * *}$ & 0.000 \\
\hline & $a^{*}$ & 9.55 & 1.69 & 12.05 & 2.08 & 10.16 & 1.78 & 13.87 & 2.34 & $10.54^{* * *}$ & 0.000 \\
\hline & $b^{*}$ & 15.67 & 1.91 & 14.90 & 1.70 & 18.86 & 1.98 & 19.18 & 1.02 & $21.03^{* * *}$ & 0.000 \\
\hline \multirow{3}{*}{ Chin } & $\mathrm{L}^{*}$ & 62.00 & 3.22 & 62.06 & 3.43 & 58.24 & 2.16 & 56.91 & 1.16 & $10.75^{* * *}$ & 0.000 \\
\hline & $a^{*}$ & 13.83 & 1.48 & 13.12 & 1.83 & 15.17 & 0.83 & 15.02 & 0.43 & $8.57^{* * *}$ & 0.000 \\
\hline & $b^{*}$ & 16.48 & 1.45 & 18.45 & 1.36 & 19.36 & 0.96 & 19.67 & 0.69 & $19.38^{* * *}$ & 0.000 \\
\hline \multirow{3}{*}{$\begin{array}{l}\text { Bottom } \\
\text { of chin }\end{array}$} & $L^{*}$ & 66.24 & 1.45 & 65.64 & 1.80 & 63.47 & 1.65 & 62.41 & 2.36 & $12.87^{* * *}$ & 0.000 \\
\hline & $a^{*}$ & 9.87 & 1.44 & 10.60 & 1.28 & 11.36 & 1.41 & 11.15 & 1.68 & $3.52^{*}$ & 0.021 \\
\hline & $b^{*}$ & 16.34 & 1.85 & 17.50 & 2.27 & 18.91 & 2.12 & 20.61 & 2.26 & $7.75^{* * *}$ & 0.000 \\
\hline \multirow{3}{*}{ Lip } & $L^{*}$ & 49.14 & 2.04 & 49.42 & 2.66 & 48.70 & 2.82 & 44.63 & 2.61 & $5.59^{* * *}$ & 0.000 \\
\hline & $a^{*}$ & 21.42 & 1.67 & 21.46 & 2.50 & 22.37 & 2.98 & 24.37 & 2.09 & 2.52 & 0.067 \\
\hline & $b^{*}$ & 14.17 & 1.04 & 13.32 & 1.34 & 14.05 & 1.27 & 14.02 & 1.84 & 1.50 & 0.226 \\
\hline \multirow{3}{*}{ Palm } & $L^{*}$ & 67.87 & 1.69 & 66.81 & 1.92 & 65.91 & 2.52 & 64.26 & 1.77 & $5.13^{* *}$ & 0.003 \\
\hline & $a^{*}$ & 8.38 & 1.46 & 9.05 & 1.10 & 9.53 & 1.68 & 11.13 & 1.53 & $5.47^{* *}$ & 0.002 \\
\hline & $b^{*}$ & 15.38 & 2.32 & 17.21 & 1.89 & 18.49 & 2.50 & 19.92 & 1.69 & $8.44^{* * *}$ & 0.000 \\
\hline \multirow{3}{*}{ Total } & $\mathrm{L}^{*}$ & 62.37 & 1.54 & 61.77 & 1.73 & 59.49 & 1.34 & 57.39 & 1.16 & $23.38^{* * *}$ & 0.000 \\
\hline & $a^{*}$ & 12.38 & 0.87 & 12.96 & 1.11 & 13.69 & 0.79 & 14.99 & 0.73 & $13.97^{* * *}$ & 0.000 \\
\hline & $b^{*}$ & 15.54 & 1.00 & 16.42 & 0.96 & 18.14 & 1.12 & 19.03 & 0.76 & $28.89^{* * *}$ & 0.000 \\
\hline
\end{tabular}

${ }^{*} p<0.05 ;{ }^{* *} p<0.01 ;{ }^{* * *} p<0.001 ; \mathrm{M}$, mean; SD, standard deviation. 
컬러인 고채도, 중명도의 오렌지 립스틱을 반쪽 적용하고 반대 쪽엔 워스트 컬러인 저명도, 저채도 오렌지 립스틱을 적용했을 때의 모 습이다. 베스트 컬러를 적용한 후 얼굴 주변은 피부가 투명하고 균 일해지는 것을 알 수 있었다. 반면 워스트 컬러를 적용한 반쪽 얼굴 에는 주름과 잡티가 도드라져 나이 들어 보였다. Table 5-2의 연구 대상자는 웜톤 봄 미디엄 유형으로 중명도의 립스틱 보다 고명도의 립스틱이 확연히 떠 보이는 것을 알 수 있었다. 같은 웜톤 봄 립스틱
이라고 하더라도 명도차에 의해 구분이 되고 어울리지 않았다. 실제 연구대상자들은 시중에 나와있는 윔톤 봄 립스틱이라고 해서 사용 해봤지만 명도차로 인해 부담스러워서 사용하지 못하는 경우가 많 았다고 전했다. 본인 유형에서 명도차를 구분하지 못하고 적용하면 이미지와 같이 떠 보이는 현상을 볼 수 있다. Table 5-3은 퍼스널 컬러 진단 시 웜톤과 쿨톤의 구분을 위해 활용하는 드레이프 대표색 상을 립스틱에 적용해 보았다. 웜톤의 베스트 컬러인 고채도 중명도

Table 4. Comparative analysis on facial color after seasonal-type drape and lipstick application

\begin{tabular}{|c|c|c|c|c|c|c|}
\hline & Classification & & Drape & Lipstick & $x^{2}$ & $p$ \\
\hline \multirow{18}{*}{ Change off skin color } & \multirow{3}{*}{ Redness or Yellowness } & Decrease & $51(85.0)$ & $54(90.0)$ & \multirow{3}{*}{0.69} & \multirow{3}{*}{0.408} \\
\hline & & Increase & $0(0.0)$ & $0(0.0)$ & & \\
\hline & & Unchanged & $9(15.0)$ & $6(10.0)$ & & \\
\hline & \multirow{3}{*}{ Lightness } & Lighten & $56(93.3)$ & $56(93.3)$ & \multirow{3}{*}{0.00} & \multirow{3}{*}{1.000} \\
\hline & & Darken & $0(0.0)$ & $0(0.0)$ & & \\
\hline & & Unchanged & $4(6.7)$ & $4(6.7)$ & & \\
\hline & \multirow{3}{*}{ Chroma } & Become transparent & $42(70.0)$ & $43(71.7)$ & \multirow{3}{*}{0.35} & \multirow{3}{*}{0.842} \\
\hline & & Become opaque & $2(3.3)$ & $1(1.7)$ & & \\
\hline & & Unchanged & $16(26.7)$ & $16(26.7)$ & & \\
\hline & \multirow{3}{*}{ Uniformity } & Looks uniform & $58(96.7)$ & $54(90.0)$ & \multirow{3}{*}{2.14} & \multirow{3}{*}{0.143} \\
\hline & & Looks uneven & $0(0.0)$ & $0(0.0)$ & & \\
\hline & & Unchanged & $2(3.3)$ & $6(10.0)$ & & \\
\hline & \multirow{3}{*}{ Complexion } & Look better & $55(91.7)$ & $57(95.0)$ & \multirow{3}{*}{0.54} & \multirow{3}{*}{0.464} \\
\hline & & Look worse & $0(0.0)$ & $0(0.0)$ & & \\
\hline & & Unchanged & $5(8.3)$ & $3(5.0)$ & & \\
\hline & \multirow{3}{*}{ Skin } & Look better & $46(76.7)$ & $43(71.7)$ & \multirow{3}{*}{0.39} & \multirow{3}{*}{0.532} \\
\hline & & Look worse & $0(0.0)$ & $0(0.0)$ & & \\
\hline & & Unchanged & $14(23.3)$ & $17(28.3)$ & & \\
\hline \multirow{12}{*}{ Change of facial shape } & \multirow{3}{*}{ Third dimension } & Third dimensional & $30(50.0)$ & $38(63.3)$ & \multirow{3}{*}{2.17} & \multirow{3}{*}{0.141} \\
\hline & & Flat & $0(0.0)$ & $0(0.0)$ & & \\
\hline & & Unchanged & $30(50.0)$ & $22(36.7)$ & & \\
\hline & \multirow{3}{*}{ Facial angle } & Smoothen & $45(75.0)$ & $35(58.3)$ & \multirow{3}{*}{4.33} & \multirow{3}{*}{0.115} \\
\hline & & Roughen & $0(0.0)$ & $1(1.7)$ & & \\
\hline & & Unchanged & $15(25.0)$ & $24(40.0)$ & & \\
\hline & \multirow{3}{*}{ Blemish, Freckle, Acne } & Become faint & $47(78.3)$ & $43(71.7)$ & \multirow{3}{*}{0.71} & \\
\hline & & Deepen & $0(0.0)$ & $0(0.0)$ & & 0.399 \\
\hline & & Unchanged & $13(21.7)$ & $17(28.3)$ & & \\
\hline & & Become faint & $55(91.7)$ & $46(76.7)$ & & \\
\hline & Wrinkle, Shade & Deepen & $0(0.0)$ & $0(0.0)$ & $5.07^{*}$ & 0.024 \\
\hline & & Unchanged & $5(8.3)$ & $14(23.3)$ & & \\
\hline & & Harmonious & $58(96.7)$ & $60(100.0)$ & & \\
\hline Change of appearance & General image & Incongruous & $0(0.0)$ & $0(0.0)$ & 2.03 & 0.399 \\
\hline & & Unchanged & $2(3.3)$ & $0(0.0)$ & & \\
\hline & Total & & 60 (100.0) & 60 (100.0) & & \\
\hline
\end{tabular}

${ }^{*} p<0.05$. 
오렌지 립스틱과 쿨톤의 베스트 컬러인 핑크 립스틱을 선정하였다. 연구대상자는 윔톤 봄 미디엄 유형으로 반쪽씩 입술에 적용했을 때 자신과 맞는 퍼스널 컬러 립스틱 색상은 밀착되고 주변의 피부가 밝 아지며 균일하다고 느꼈다. 반면 워스트 컬러를 적용했을 때 입술이 떠 보이고 피부 주변에 노란기와 붉은기가 올라오는 것을 알 수 있었 다. Table 5-4 연구대상자는 웜톤 봄 다크 유형으로 엘로우 베이스 가 섞인 고채도 중명도의 레드 립스틱이 가장 베스트 컬러이다. 같은 고채도의 레드 립스틱이라고 하더라도 베이스에 블루가 섞인 립보다 엘로우가 섞인 립이 가장 잘 어울리는 것을 알 수 있다. 웜톤 봄 유형 이 레드 립스틱을 많이 사용하는데 기본 베이스가 블루가 섞였는지 엘로우가 섞였는지에 따라 다르다는 걸 알 수 있다. Table 5-5 연구 대상자는 쿨톤 여름 라이트 유형으로 오렌지 립스틱을 적용했을 때 노란기가 증가하여 연구대상자 본인이 무겁고, 답답하고, 조화롭지 않다고 느꼈다. 핑크 립스틱을 적용했을 때 의외로 붉은기가 살짝 올 라오기는 하지만 피부가 투명해지는 것을 알 수 있었다. Table 5-6 연구대상자는 쿨톤 여름 미디엄 유형으로 같은 핑크색 립스틱을 적 용하더라도 고명도의 핑크색보다 중명도 저채도의 핑크색 립스틱을 적용했을 때 차분하게 밀착되는 것을 알 수 있었다. 많은 연구대상자 가 동양인이 가진 노란기와 고명도 핑크색이 어울리지 않는다는 이 유로 웜톤으로 생각하는 경우가 많았다. Table 5-7 연구대상자는 웜 톤 가을 라이트 유형으로 가을의 베스트 컬러 립스틱인 저채도 저명 도의 립스틱을 적용했을 때 주름과 그늘이 지며 나이가 들어 보이고 명도가 무겁게 낮아지는 것을 알 수 있었다. 피부가 밝은 가을유형 이어서 중명도의 립스틱을 적용했을 때 투명하고 부드러운 이미지로
보였다. Table 5-8 연구대상자는 웜톤 가을 라이트 유형으로 이와 같은 가을 유형 중에는 피부가 밝아 웜톤 봄 유형으로 생각하는 경우 가 많았다. 대부분 쨍한 컬러가 어울리지 않아 흰끼가 도는 저채도 립을 쓰는 경우도 많았다. Table 5-9 연구대상자는 웜톤 가을 다크 유형으로 가을 유형 중 가장 낮은 피부 밝기를 가졌다. 대부분 웜톤 가을 연구대상자들이 사용하고 있는 립스틱과 베이스를 검토해본 결 과 채도가 높은 오렌지 립스틱을 사용하는 경우가 많았다. 이는 건강 한 구리빛 피부를 가지고 있지만 대부분 흰 피부를 선호하여 베이스 색을 한 톤에서 두 톤 밝게 연출하고 웜톤이 가지고 있는 노란기와 선호하는 베이스색이 밝아지면서 웜톤 봄의 유형으로 생각하는 경우 가 많았기 때문이다. 하지만 시간이 지나면서 자기 피부 온도와 환경 에 의해 색이 다운이 되면서 본래 자기의 피부톤으로 가까워지면 조 화롭지 않다고 느꼈다. 베스트 컬러 적용 후 연구대상자들은 기존에 사용하던 오렌지 립스틱이 밀착되지 않고 피부색에서 떠 보이는 것 을 직접 확인하였고, 평소 사용하지 않던 색상이 베스트 컬러이며 조 화로운 것을 알 수 있었다.

Table 5-10 연구대상자는 웜톤 가을 다크 유형으로 가을 라이트 유형의 립스틱을 적용했을 때 립스틱을 바르지 않은 것 같았다. 가을 다크 유형일수록 저명도, 저채도의 립스틱을 적용했을 때 얼굴이 이 목구비가 뚜렷해지고 균일해지는 것을 알 수 있었다. Table 5-11 연 구대상자는 쿨톤 겨울 미디엄 유형으로 고채도의 레드 립스틱이라고 하더라도 엘로우가 섞인 레드 립스틱 보다 블루가 섞인 레드 립스틱 을 적용했을 때 가장 세련되고 선명한 인상을 받을 수 있었다. Table 5-12 연구대상자는 쿨톤 겨울 다크 유형이다. 대부분 겨울 다크 유

Table 5. Image after applying best and worst lipstick colors

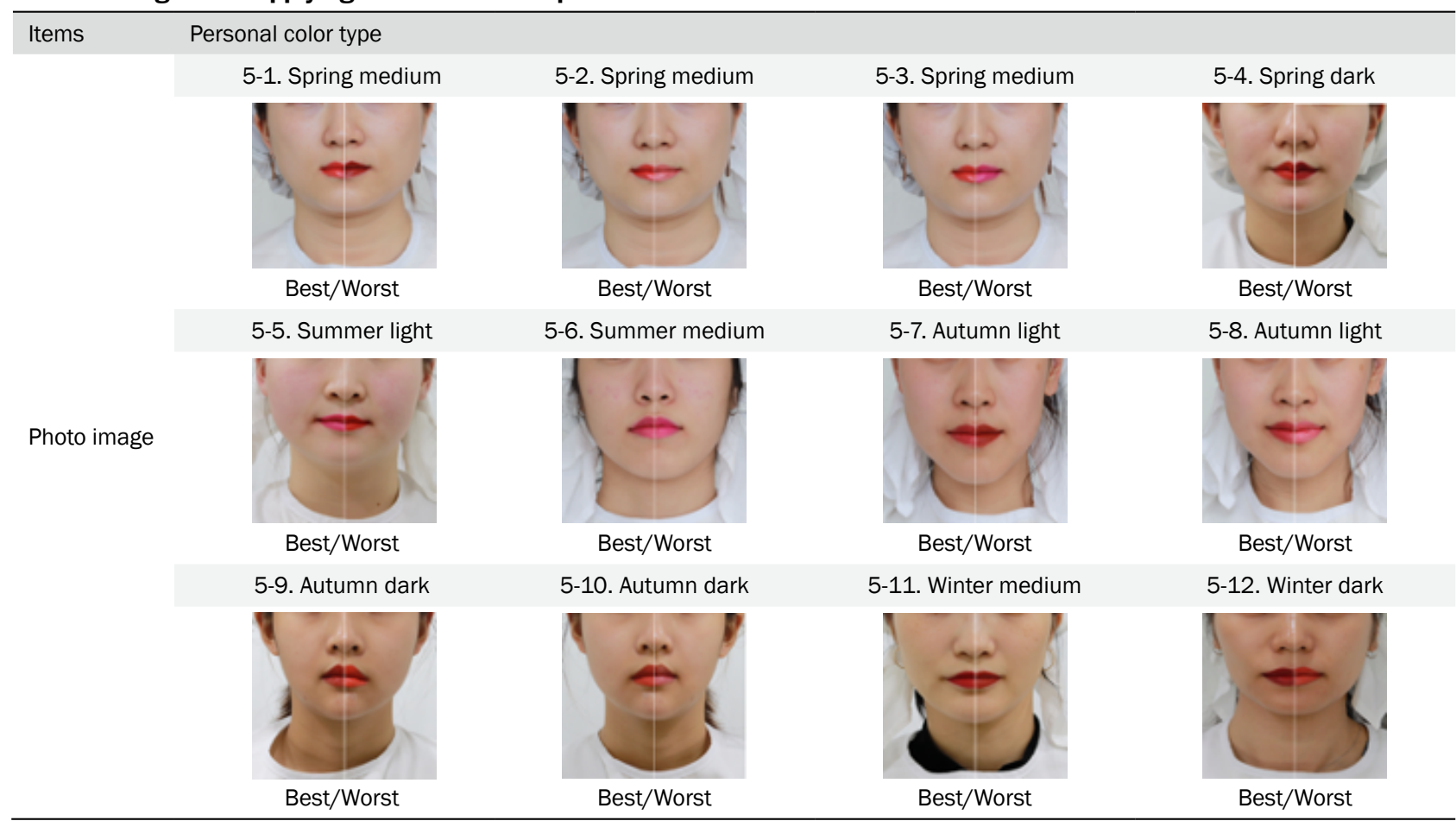


형은 동양인이 가지고 있는 노란기와 다른 유형보다 어두운 피부톤 으로 웜톤 가을 유형으로 생각한다. 본 연구에서 분광 측색기로 측색 한 결과 $\mathrm{L}^{*}$ 값이 낮고 $\mathrm{a}^{*}, \mathrm{~b}^{*}$ 값이 다른 계절 보다 높은 것이 특징이었 다. 이는 피부의 명도가 낮고 붉은기와 노란기가 있어 더 어두워 보 이는 것이다. 앞서 언급한 것과 같이 흰 피부를 선호하여 베이스 색 을 밝게 연출하며 윔톤의 고채도 엘로우가 섞인 립스틱을 사용했다. 고채도의 립스틱이 잘 어울려서 윔톤의 고채도 립스틱도 나쁘지 않 다고 생각한 결과이다. 하지만 각각 적용해 본 결과 확연히 고채도의 저명도 립을 사용했을 때 조화를 이루는 것을 알 수 있었다.

사용하고 있는 화장품색채 사용 실태조사를 하면서 립스틱을 섞 어서 쓰는 경우가 많았다. 면담을 통해 조사해본 결과 첫번째 시중에 많은 색상의 립스틱 컬러가 있지만 자신에게 어울리는 색을 찾지 못 해 원하는 색이 없다고 느겼고, 섞어서 연출했을 때 립 컬러감이 풍 부하게 표현되어 한 가지만 발랐을 때 보다 더 원하는 색감을 얻는 걸 알 수 있었다. 또한 자신과 어울리지는 않지만 선호하는 색상으 로 사용하고 싶어 하는 연구대상자의 니즈를 파악할 수 있었다. 두 번째 대중매체 및 소셜 미디어의 발색을 보고 구입했으나 립스틱마 다 발색력의 차이가 커서 기존의 제품과 섞어 바른 경우와 유행하는 색 혹은 새로 나온 신상이라고 추천 받거나 지인에게 선물을 받았지 만 피부색과 어울리지 않아서 버리지 못하고 아까워서 섞어 쓰는 경 우가 있었다. 이는 추천을 받거나 유행에 따라 혹은 지인의 선물 등 으로 피부색을 고려하지 않아 나타난 결과이다. 유행하는 색상은 분 명 그 사람을 트렌디하게 보이게 하지만 자칫 잘못하면 촌스러워 보 일 수도 있다. 이런 이미지는 립스틱 적용 시 즉각적으로 발현되어 단독으로 쓰지 못하는 경우를 사례로 볼 수 있었다. 화장품색채 사용 실태조사 후 2 차 시험 연구에서 자신에게 어울리는 색상의 립스틱으 로 얼굴의 피부색 변화도를 체크할 때 자신이 사용해본 적 없는 립스 틱 색상을 입술에 직접적으로 적용해 조화로운 것을 보고 놀라는 경 우가 많았다. 이는 자신에게 어울리는 컬러 즉, 퍼스널 컬러의 유형 을 몰라서 립스틱 색상을 찾기 힘들고 어려웠던 이유이기도 하였다. 또한 자신의 유형을 알아도 light, medium, dark 명도별 즉, 피부의 밝기별 세부적인 유형에 따라서 어울리는 립스틱 컬러가 달라지기 때문에 섞어서 사용하거나 사용하지 못한 이유라고 사료된다. 그 중 에는 자신에게 어울리는 색을 잘 알고 색을 섞어 쓰는 유형도 있었을 것이지만 대부분의 연구 대상자들은 어울리는 컬러를 몰라서 섞어 사용하는 결과가 나왔다고 사료된다. 사진상에 한계가 있지만 연구 를 진행하며 연구대상자가 직접 자신의 변화를 뚜렷하게 알 수 있었 고 드레이프를 적용했을 때와 유의미한 차이가 없음을 느끼며 이상 과 같은 결과를 통해 립스틱 컬러만으로도 유형을 분류할 수 있음을 예측할 수 있었다. 여성들의 퍼스널 컬러 유형에 따라 립스틱 컬러를 적용한 후 얼굴 피부색의 조화요인과 부조화요인에 대해 살펴본 결 과는 Table 5 와 같다.

\section{Conclusion}

본 연구는 우리나라 여성들의 퍼스널 컬러 유형에 대한 기본 정보 를 구축하고, 립스틱 컬러만으로도 유형을 분류할 수 있는 시스템을 마련하는 데 그 목적을 두고, 건국대학교 기관생명윤리위원회(IRB) 의 연구승인을 받고 진행하였다. 수도권에 거주하는 20-39세의 건 강한 여성들 60 명을 대상으로 2019년 11월 8일부터 11월 18일까지 총 11 일간에 걸쳐 1,2 차 측정을 통하여 4 계절 유형을 토대로 명도 를 나타내는 light, medium, dark 3 가지 피부 명도를 분류하여 퍼 스널 컬러 진단 시험을 실시하였으며, 시험 전후 설문 조사 시 심층 면담을 병행하여 직접 설문지에 기입하는 방식으로 조사하였다. 수 집된 자료는 SPSS WIN 25.0 프로그램을 이용하여 분석하였으며, $x^{2}$-test와 빈도분석, One-way ANOVA로 분석하여 다음과 같은 결 과를 얻었다.

첫째, 여성들의 퍼스널 컬러 유형에 따라 드레이프 적용 후 얼 굴 피부색의 조화 여부에 대해 살펴본 결과, 조화요인 중 피부색 변 화에서 붉은색 및 노란색 감소는 겨울 유형이, 밝아진다에 대해서 는 봄과 여름 유형이, 투명해진다에 대해서는 여름 유형이 각각 다 른 유형보다 높은 반응을 보였으며, 균일해 보인다에 대해서는 봄과 가을, 여름 유형이, 혈색이 좋아 보인다에 대해서는 겨울 유형이, 피 부가 좋아 보인다에 대해서는 여름 유형이 각각 다른 유형보다 높은 반응을 보였다. 얼굴형태 변화에서 입체적이다에 대해서는 겨울 유 형이, 얼굴의 각이 부드러워 진다에 대해서는 가을 유형이, 잡티, 기 미, 여드름이 희미해진다에 대해서는 여름 유형이, 주름, 그늘이 옅 어진다에 대해서는 가을 유형이 높은 반응을 보였다. 인상변화에서 전체적인 분위기가 조화롭다에 대해서는 봄과 가을 유형이 다른 유 형보다 높은 반응을 보였다.

둘째, 부조화요인 중 피부색 변화와 얼굴형태 변화, 인상 변화는 퍼스널 컬러 유형별에는 별다른 차이 없이 부조화요인이 없는 것으 로 나타났다.

셋째, 퍼스널 컬러 유형에 따라 립스틱 컬러를 적용한 후에 얼굴 피부색의 변화에 대해 살펴본 결과, 피부색 변화에서 색상과 명도는 퍼스널 컬러 유형에 관계없이 모두 변화가 있었으며, 혈색 또한 유 형에 관계없이 모두 변화가 있는 것으로 나타났다. 얼굴형태 변화 중 입체성은 여름 유형이 다른 유형보다 변화가 없었고, 얼굴의 각 은 겨울 유형이, 잡티, 기미, 여드름과 주름, 그늘은 가을 유형이 다 른 유형보다 변화가 없는 것으로 나타났다. 인상 변화에서 전체적인 분위기와 입술변화에서 립스틱과 입술의 밀착성에 대해서는 퍼스널 컬러 유형에 관계없이 모두 변화가 있는 것으로 나타났다. 사진상에 한계가 있지만 연구를 진행하며 연구대상자가 직접 자신의 변화를 뚜렷하게 알 수 있었고 드레이프를 적용했을 때와 유의미한 차이를 느끼지 못했으며 이상과 같은 결과를 통해 립스틱 컬러만으로도 유 형을 분류할 수 있음을 예측할 수 있었다.

본 연구는 연구대상자 선정에 있어 수도권 지역을 대상으로 하여, 
연구결과를 모든 한국 여성들에게 일반화하기에는 다소 부족함이 있었으며, 퍼스널 컬러 유형을 더 심도 있게 판별할 수 있는 표본의 크기에 있어 부족하였으나, 진단천 없이 립스틱 컬러만으로도 유형 을 분류할 수 있는 시스템을 구상한 본 연구가 퍼스널 컬러 시스템 을 바탕으로 한 뷰티 관련 재교육 및 이미지 컨설팅 등의 분야에서 기초 자료로 활용되기를 기대한다.

This work is a part of the Do-Eun Kim's M.Sc. thesis at the Konkuk University, Seoul, Korea.

\section{Author's contribution}

DEK performed experiments and DEK and YSK designed, analyzed data, and wrote the manuscript together. All figures are created by the authors. All authors read and approved the final manuscript.

\section{Author details}

Do-Eun Kim (Graduate student), Department of Cosmetics Engineering, Graduate School of Konkuk University, 120 Neungdong-ro Gwangjin-gu, Seoul 05029, Korea; YoungSam Kim (Professor), Department of Image Industry, Graduate School of Engineering, Konkuk University, 120 Neungdong-ro, Gwangjin-gu, Seoul 05029, Korea.

\section{References}

Baek GJ, Kim MY. Make-up behavior and influential factors: focusing on clothing involvement, age and face satisfaction. Journal of the Korean Society of Clothing and Textiles, 28: 1372-1383, 2004.

Cho MJ. Analysis of image makeup using color trends. Asian Journal of Beauty and Cosmetology, 16: 499-507, 2018.

Cho MJ, Yang JH. Image perception according to face shapes and makeup color variation. Asian Journal of Beauty and Cosmetology, 15: 122-131, 2017.

Hong MS. Study on the lip color of Korean. Korean Society of Color Design Studies, 2005: 48-50, 2005.

Hwang YJ, Jo KY, Yoo TS. The study on cosmetic surgery behavior according to appearance concern, body cathexis, and self-esteem. Journal of Fashion Business, 7: 17-25, 2003.

Im Ej, Park MS, Ha JH. The correlation among perception and application of personal color and beauty styling: women in their 20s. Journal of Investigative Cosmetology, 13: 369-379, 2017.

Jackson C. Color me beautiful: discover your natural beauty through the colors that make you look great and feel fabulous. Ballantine Books, New York, p38, 1987.

Jin HY, Cho HJ. A case study on the application of an image making: focused on Korea women age around 20-30. The Journal of the Korean Society of Make-up Design, 5: 29-38, 2009.

Kim JD. A study on the actual condition of using low-priced cosmetics and on the purchasing behavior in female undergraduates. Journal of the Society of Cosmetic Scientists of Korea, 37: 177-189, 2011.

Kim HM, Youn CS. Study on validity of personal color selfdiagnosis measurement scale. Journal of the Korean Society of Cosmetology, 24: 689-696, 2018.

Kim HS, Kang IA. A study on the image make-up according to theme. Journal of Fashion Business, 7: 72-83, 2003.

Kim MK. Correlation between the factors of personal color diagnosis guide and brain wave analysis. Asian Journal of Beauty and Cosmetology, 14: 407-416, 2016.

Kim YH, OH YS, Lee JH. Research of quantitative modeling that classify personal color skin tone. Journal of the Korean Society of Clothing and Textiles, 42: 121-132, 2018.

Ko HS, Ryu JW. The effect of female's lip color and subject's traits on the impression formation. The Journal of the Korean Society of Make-up Design, 5: 203-214, 2009.

Kwon TI, Heo HS. Appearance satisfaction and self-esteem according to the actual situation of eyelash beauty. Asian Journal of Beauty and Cosmetology, 17: 295-306, 2019.

Lee EY, Park KS. Analysis of facial coloration in accordance with the type of personal color system of female university students. The Research Journal of the Costume Culture, 20: 144-158, 2012.

Lee J, Yuchun Y, Suk HJ. Analysis of measured, reported, and pursued skin color. Korean Society of Color Studies, 2018: 46-49, 2018.

Min IS, Park JH, Lim JH, Park EJ. How to uniform satisfaction affected by uniform recognition in the beauty services workers. Asian Journal of Beauty and Cosmetology, 11: 289-296, 2013.

Moon W, Park Y. Personal color analysis through relation between timber, skin tone and iris color. Journal of Korea 
Society of Color Studies, 28: 15-25, 2014.

Oh RB, Cho MJ. The development of nail art design utilizing the Panton color trend. Journal of the Korean Society of Cosmetology, 24: 133-142, 2018.

Park EA. Psychosocial meaning of make-up. The Korean Journal of Consumer and Advertising Psychology, 4: 105127, 2003.

Park HS. Personal color types classified by skin and hair colors of college students in Taegu and Kyungbuk area. Journal of the Korean Society of Clothing and Textiles, 25: 516-524, 2001.

Park JE, Jin BU, Park EJ. Knowledge sharing between beauty industry workers based on general individual and organizational characteristics. Asian Journal of Beauty and Cosmetology, 18: 79-93, 2020.

Park YS, Chun HK, Yim EH. Qualitative research on motivations, decision-makers, and effects of personal color consulting. Journal of Fashion Design, 19: 37-56,
2019.

Song SM, Lee KH, Kim JH. Color effects as affected by concentration rate of pearlescent pigment in eyeshadows. Journal of the Korean Society of Beauty and Art, 15: 7-20, 2014.

Sim YJ, Choi JS. A study on the development direction of the beauty industry according to the 4th industrial revolution. Journal of the International Society of Nail Beauty Design, 5: 29-35, 2017.

Woo SJ, Kim YS. A study on the point makeup purchasing and using behavior according to the personal color awareness. The Research Journal of the Costume Culture, 19: 889-902, 2011.

Whang SM, Jung JW, Kim JI, Kyon KS, Choi YM. The psychological analysis of color image: color makeup and its color image by consumers' character \& life style. Korean Society of Color Studies, 1999: 23-32, 1999. 


\section{국문초록}

\section{립스틱 색채를 이용한 퍼스널 컬러 유형 분류 연구}

김도은 ${ }^{1}$, 김영삼 ${ }^{2 *}$

${ }^{1}$ 건국대학교 화장품공학과, 서울, 한국

${ }^{2}$ 건국대학교 산업대학원 이미지산업학과, 서울, 한국

목적: 본 연구는 립스틱 색채를 이용하여 퍼스널 컬러 유형을 분류할 수 있는지 검증하고자 한다. 방법: 수도권에 거주하는 20-39 세의 여성 60명을 대상으로 자료를 수집하였고, SPSS WIN 25.0 프로그램을 이용하여 분석하였으며, $\chi^{2}$ (Chi-Square)-Test와 빈 도분석, One-way ANOVA, Cluster Analysis와 Discriminant Analysis를 실시하였다. 결과: 베스트 컬러의 드레이프를 적용한 변화 도와 립스틱 컬러를 적용한 후에 나타난 피부색의 변화도에서 유의미한 차이가 보이지 않아 드레이프 없이 립스틱 컬러만으로도 유 형을 분류하는데 도움이 되는 것을 알 수 있었다. 결론: 본 연구는 퍼스널 컬러 유형에 따른 진단 천과 립스틱 색채의 상관관계를 증 명하였고, 퍼스널 컬러 진단 천 없이 립스틱 색채만으로도 그 유형을 분류할 수 있는 시스템을 구상할 수 있다는 것을 확인하였다. 이러한 이론을 근거로 뷰티 분야에 기초 자료로 활용할 수 있을 것이다.

핵심어: 퍼스널컬러, 메이크업, 립스틱, 이미지, 화장품색채

\section{참고문헌}

고혜숙, 류지원. 여성 메이크업의 입술컬러와 지각자의 특성이 인상형성에 미치는 영향. 한국메이크업디자인학회지, 5 : 203-214, 2009.

권태일, 허혜순. 속눈썹 미용실태에 따른 외모만족도와 자아존중감. 아시안뷰티화장품학술지, 11: 289-296, 2013. 김민경. 퍼스널 컬러진단 가이드 요인간 상관관계와 뇌파분석. 아시안뷰티화장품학술지, 14: 407-416, 2016.

김용현, 오유석, 이정훈. 퍼스널 컬러 스킨 톤 유형 분류의 정량적 평가 모델 구축에 대한 연구. 한국의류학회지, 42 :

121-132, 2018.

김주덕. 여대생들의 저가 화장품에 대한 사용실태 및 구매행동에 관한 연구. 대한화장품학회지, 37: 177-189, 2011. 김현미, 윤천성. 퍼스널컬러 자가진단 측정 척도 타당성 연구. 한국미용학회지, 24: 689-696, 2018.

김효숙, 강인애. 테마별 이미지 Make-up에 관한 연구. 패션비즈니스, 7: 72-83, 2003.

문완묵, 박연선. 음색과 피부색, 홍채색의 상관관계를 통한 퍼스널 컬러 분석. 한국색채학회논문집, $28: 15-25,2014$ 민인숙, 박재홍, 임지현, 박은준. 미용서비스업 종사자의 유니폼 개선사항에 미치는 영향. 아시안뷰티화장품학술지, $11:$

289-296, 2013.

박유선, 전호경, 임은혁. 퍼스널 컬러 컨설팅 시행의 동기와 의사결정 요인, 효과에 대한 질적연구. 한국패션디자인학회지,

19: 37-56, 2019.

박은아. 화장의 심리사회적 의미: "보여주기"의 미학. 한국심리학회지: 소비자·광고, 4: 105-127, 2003.

박정은, 진병운, 박은준. 미용서비스업 종사자의 특성에 따른 지식공유. 아시안뷰티화장품학술지, 18: 79-93, 2020.

박화순. 대학생들의 피부색과 머리카락색에 따른 개인색채 유형 분류: 대구경북지역을 중심으로. 한국의류학회지, 25:

516-524, 2002.

백경진, 김미영. 화장품 구매행동과 영향 변인 연구: 의복관여도, 연령, 얼굴만족도를 중심으로. 한국의류학회지, 28 :

1372-1383, 2004.

송수미, 이경희, 김정희. 아이 새도의 광택 안료 함유량에 따른 발색효과. 한국인체미용예술학회지, 15: 7-20, 2014.

심예진, 최정순. 4 차 산업혁명에 따른 뷰티 산업의 발전 방향성에 관한 연구. 한국네일미용학회지, $5: 29-35,2017$. 
오란비, 조미자. 컬러트렌드를 활용한 네일아트 디자인 연구-팬톤의 컬러트렌드를 중심으로. 한국미용학회지, $24: 133-$ 142, 2018.

이은영, 박길순. 여대생의 퍼스널 컬러 시스템 유형에 따른 얼굴색 분석. 복식문화연구, 20: 144-158, 2012.

이주현, Yan Yuchun, 석현정. 측색, 주관적 판단, 그리고 추구하는 피부색 간 관계 분석. 한국색채학회 학술대회, 2018: 46-49, 2018.

우수진, 김용숙. 퍼스널 컬러 인식에 따른 색조 화장품 구입 및 사용행동. 복식문화연구, 19: 889-902, 2011.

임은진, 박명순, 하준호. 퍼스널 컬러의 인식과 활용 및 뷰티 스타일링의 상관관계: 20,30 대 여성을 중심으로. 대한미용 학회지, 13: 369-379, 2017.

진형여, 최희자, 이미지 메이킹 적용에 관한 사례연구: 우리나라 20 30대 여성들을 중심으로. 한국메이크업디자인학회 지, 5: 29-38, 2009.

조미자. 컬러 트렌드를 활용한 이미지 메이크업 분석. 아시안뷰티화장품학술지, 16: 499-507, 2018.

조민희, 양진희. 얼굴형과 메이크업의 색상변화에 따른 이미지 지각에 관한 연구. 아시안뷰티화장품학술지, 15: 122$131,2017$.

홍미숙. 한국인의 입술 색에 관한 연구. 한국색채디자인학회 학술대회, 2005: 48-50, 2005.

황상민, 정주원, 김종일, 권기선, 최유미. 색채 이미지의 심리적 분석. 한국색채학회 학술대회, 1999: 23-32, 1999.

황윤정, 조기여, 유태순. 외모관심도, 신체만족도, 자아존중감에 따른 미용성형행동 연구. 패션비즈니스, 7: 17-25, 2003. 


\section{中文摘要}

\section{利用口红颜色对个人色彩进行分类}

金到垠 ${ }^{1}$, 金永三 $^{2 *}$

建国大学化妆品工学科, 首尔, 韩国

2建国大学产业大学院影像产业学科, 首尔, 韩国

目的: 验证是否可以利用口红色彩来分类个人色彩类型。方法：以居住在首都圈的20-39岁的60名女性为对象收 集资料, 采用SPSS WIN 25.0软件进行统计分析, 进行频数分析、百分率、 $t$ 检验、单因素方差分析、 $x^{2}$ 检验和 回归分析。结果: 在使用相配的布的变化度和使用口红色彩后出现的肤色变化度上, 出现了细微的差异, 可以看 出在没有诊断布的情况下，仅以口红色彩就足以帮助分类类型。结论: 在这项研究中，证明了诊断布和口红颜色 根据个人颜色类型之间的相关性, 并证实了可以构想出一种系统, 该系统可以单独使用口红颜色进行分类, 而 无需使用个人颜色诊断布。基于这一理论，它可以作为美容领域的基础材料。

关键词: 个人色彩, 化妆, 口红, 形象, 化妆色彩 